Case Report

\title{
Mullerian-Type Ciliated Cyst of the Thigh with PAX-8 and WT1 Positivity: A Case Report and Review of the Literature
}

\author{
Corinthia Fabien-Dupuis, ${ }^{1,2,3}$ Brian Cooper, ${ }^{1}$ Jeffrey Upperman, ${ }^{2,4}$ \\ Shengmei Zhou, ${ }^{1,2}$ and Nick Shillingford ${ }^{1,2}$ \\ ${ }^{1}$ Department of Pathology and Laboratory Medicine, Children's Hospital Los Angeles, Los Angeles, CA, USA \\ ${ }^{2}$ Keck School of Medicine of the University of Southern California, Los Angeles, CA, USA \\ ${ }^{3}$ Department of Pathology, Queen Elizabeth Hospital, Bridgetown, Barbados \\ ${ }^{4}$ Department of Surgery, Children's Hospital Los Angeles, Los Angeles, CA, USA
}

Correspondence should be addressed to Nick Shillingford; nshillingford@chla.usc.edu

Received 7 September 2016; Accepted 14 November 2016

Academic Editor: Christian Koch

Copyright (c) 2016 Corinthia Fabien-Dupuis et al. This is an open access article distributed under the Creative Commons Attribution License, which permits unrestricted use, distribution, and reproduction in any medium, provided the original work is properly cited.

\begin{abstract}
Mullerian-type ciliated cysts are uncommon lesions usually found in the lower extremities and perineal region of young females. They have however been reported in males and in other anatomic sites. The cyst lining is typically positive for estrogen receptor (ER), progesterone receptor (PR), PAX-8, and WT1 immunohistochemical stains. This staining pattern has led to the notion that these cysts are of Müllerian origin. The vast majority of cases are located in the dermis where the preferred nomenclature is cutaneous ciliated cyst (CCC). We report a case of Müllerian-type ciliated cyst in the thigh of a 16-year-old girl. Unlike most of the cases reported in the English literature, this cyst was not centered in the dermis. Only a few other cases of Müllerian-type ciliated cysts with no cutaneous connection have been reported. We propose the term ectopic Müllerian cyst for this rare subset of lesions that are not skin based as is the current case.
\end{abstract}

\section{Introduction}

Cutaneous ciliated cysts (CCC) also known as cutaneous Mullerian cysts are rare lesions which mostly occur in the lower extremities of females [1]. Up to 2015, 60 cases of CCC had been published, of which 50 were in female patients and 10 in males. These cysts are believed to arise from ectopic Mullerian rests which become active during puberty or pregnancy [2]. We present a case of a CCC without obvious cutaneous connection occurring in the thigh of a 16-year-old girl [3]. By immunohistochemistry, estrogen receptor (ER), progesterone receptor (PR), PAX-8, and WT1 were positive in the epithelial lining of the cyst, lending support to a possible Müllerian origin [4].

\section{Case Report}

A 16-year-old girl presented with a solitary, $2 \mathrm{~cm}$, freely mobile mass in the soft tissue of the right thigh. The cyst had been present for at least 3 years. According to the patient, the mass has waxed and waned but was for the most part increasing in size. There is no associated rubor, calor, pain, tenderness, skin changes, or drainage. She denied fever, anorexia, asthenia, and weight loss. She has no significant past medical or surgical history. There is no history of pregnancy or preceding trauma. At surgery, the mass was situated in the subcutaneous soft tissue. It was incised revealing its cystic nature. The cystic fluid was expressed and the mass was completely excised and sent to the pathology department for further evaluation.

Surgical pathology received a $2.5 \mathrm{~cm}$ tan-brown collapsed unilocular cyst. Skin was not identified in the specimen on gross inspection. The cyst wall measured $0.1 \mathrm{~cm}$ in thickness. The inner lining was tan, smooth, and glistening. Representative sections were submitted for microscopic examination. On low magnification, sections showed a cystic lesion whose fibrocollagenous wall was thrown into multiple folds forming finger-like projections focally (Figure 1). A 


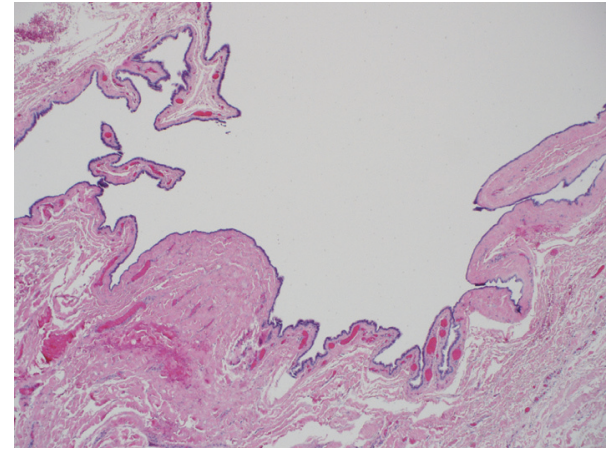

FIGURE 1: Low power photomicrograph showing a cystic mass with infoldings and excrescences of its wall at the inner aspect. The cyst lining is easily appreciated. H\&E. Magnification, 40x.

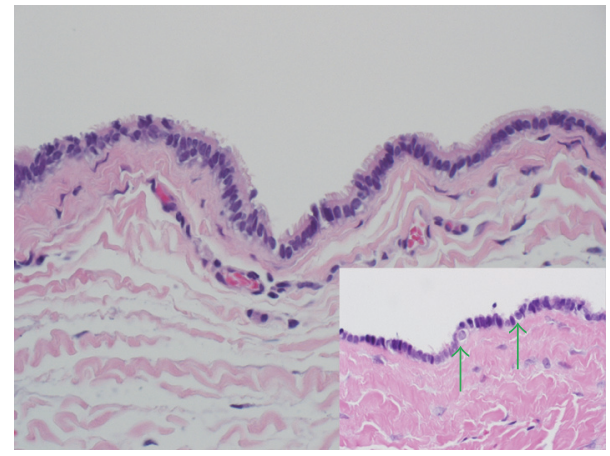

Figure 2: Higher magnification reveals that the cyst is lined by a ciliated simple columnar epithelium reminiscent of that of Mullerian derived structures. H\&E. Magnification, 400x. The inset highlights occasional cells with round nuclei and perinuclear clearing at the base of the epithelium (green arrows). These cells are similar to those seen in fallopian tube epithelium. H\&E. Magnification, 600x.

thorough search for skin appendages such as hair follicles, sebaceous glands, and sweat glands revealed no such structures. High magnification revealed a cyst lining formed by a simple ciliated cuboidal to columnar epithelium with no significant cytologic atypia (Figure 2). Pseudostratification was evidenced focally. Occasional cells with round nuclei and perinuclear clearing seen towards the base of the epithelium were reminiscent of cells seen in fallopian tube epithelium (Figure 2, inset). In the fallopian tubes these cells are thought to be intraepithelial lymphocytes. No smooth muscle, cartilage, mucus glands, or adnexa were identified in the cyst wall. There was no significant inflammation. By immunohistochemistry, the epithelial cells were positive for pancytokeratin (AE1/AE3), estrogen receptor (ER), progesterone receptor (PR), PAX-8, and WT1 (Figures 3(a), 3(b), and 3(c)). The latter 4 are markers of Mullerian origin.

\section{Discussion}

Cutaneous ciliated cyst is an uncommon lesion with only 60 cases reported in the English literature between 1890 and
2015 (Table 1). The entity was first described by Hess in the seminal paper in 1890 [5]. The term cutaneous ciliated cyst was eventually coined by Farmer and Helwig in 1978 to describe a unique type of cyst arising in the lower extremities of young women. They reported lesions occurring in 11 patients, all of whom were female, with an age range from 15 to 30 years. The average age was 22 . In their theory, they proposed that heterotopic Mullerian tissue is sequestered during embryonic development. This results in hormone responsive Mullerian rests being deposited at specific sites leading to the formation of Mullerian-type cysts after puberty when there is an increase in hormone production. These cysts may show a growth phase during pregnancy when hormonal activity is once again elevated $[1,4,6]$. The origin still remains controversial today with various theories being proposed. These theories range from the previously mentioned Mullerian heterotopia to metaplasia of sweat gland (eccrine) epithelium to embryonic remnants of the cloacal membrane $[5,6]$.

Mullerian cysts may present as solitary unilocular or multilocular lesions. The ciliated epithelial lining is reminiscent fallopian tube epithelium [5]; however squamous metaplasia may be present focally [1]. There is generally no cytologic atypia or increased mitotic activity. The majority of cysts being located in the lower limbs may be explained by the close proximity of the Mullerian ducts to the lower limbs during development. However, the presence of similar cysts at distant sites such as scalp and mediastinum may be explained by vascular or lymphatic dissemination [7].

Despite the various theories proposed with respect to their origin, the Mullerian heterotopia theory is supported by this striking resemblance to fallopian tube epithelium and by the consistent nuclear positivity for antibodies to the steroid receptors for estrogen and progesterone [6]. PAX-8, a member of the paired box (PAX) family of transcription factors which is important in the development of Mullerian and thyroid organs, has been shown to be expressed in the nuclei of the lining cells of these ciliated cysts by immunohistochemistry in recent publications [4]. This finding further supports the possibility of a Mullerian origin as PAX-8 immunohistochemical stain is currently used to identify Mullerian tumors among others. Immunostain for WT1, the product of a gene which is essential for the development of the kidneys and gonads, is also positive lending further support to a Mullerian origin of these cysts. As a matter of fact the staining pattern of the epithelium for dynein is reported to be similar to that of fallopian tubal epithelium [8].

Of note however, similar cysts have been reported in male patients $[6,9,10]$ and interestingly, at least 2 of these cases were from the scrotum [11, 12]. The presence of cysts with similar histomorphology in male patients has led some authors to gravitate towards the sweat gland origin theory as estrogen stimulation is thought to influence the development of Mullerian derived cysts. Leonforte described the first case of ciliated cyst in a male patient in 1982 and even then he noted histologic similarities to sweat glands. In his case he described the presence of PAS-positive granules and apical caps in the epithelial cells, both features of apocrine sweat glands. The presence of dilated eccrine ducts in the vicinity of 


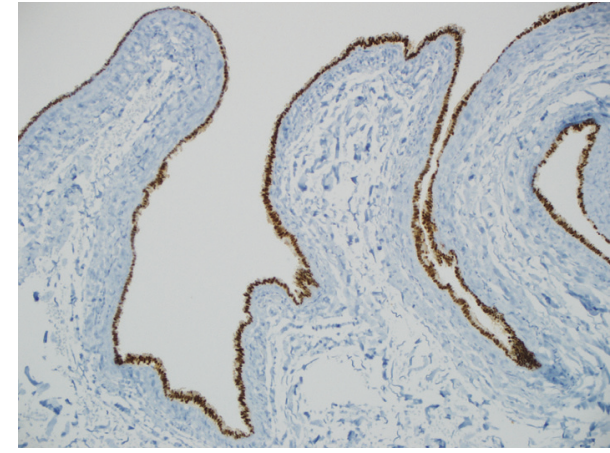

(a)

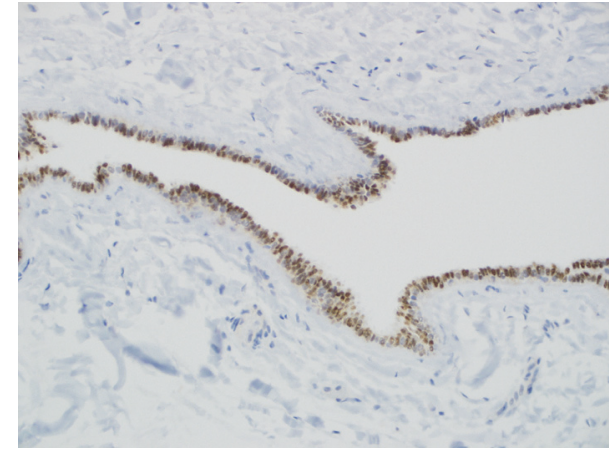

(b)

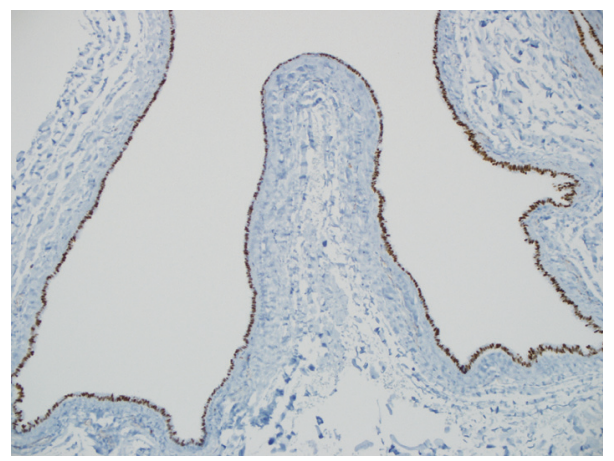

(c)

FIgURE 3: The immunohistochemical staining profile supports the notion of a Mullerian origin. Progesterone receptor immunostain shows strong and diffuse positivity in the cyst lining epithelium ((a) magnification, 100x) and PAX-8 is positive in the majority of the epithelial lining cells ((b) magnification, 200x). The lining is strongly and diffusely positive for WT1 immunostain which is localized to the nuclei ((c) magnification, 100x).

the cyst and the fact that eccrine glands are normally present in the heel, the site of the cyst in his report, and a site devoid of apocrine glands led him to suggest a possible eccrine origin. The changes in the epithelium to resemble that of fallopian tube were attributed to a metaplastic process caused by inflammation and subsequent irritation of pluripotent cells triggered by the cyst's contents [13].

In 1997 Sidoni and Bucciarelli reported a case of a ciliated cyst in the skin of the perineum of a 60 -year-old man, the origin of which they suggested was primitive caudal gut. They hypothesized that the cyst was derived from embryonic remnants of the cloacal membrane [14]. Cysts lined by nonsquamous epithelium in the perianal/perirectal region are thought to be the consequence of abnormal organogenesis of the caudal end of the embryo. The tailgut, the distalmost intestinal segment, along with the embryonic tail within which it lies undergoes complete physiologic atrophy at the 8 $\mathrm{mm}$ stage. Subsequently, the cloaca and cloacal membrane are divided by the urorectal septum giving rise to the anteriorly situated urogenital sinus and the posteriorly situated rectum. Incomplete tailgut atrophy may lead to sequestration of ectodermal and endodermal tissues into the soft tissue of the perianal and perineal regions leading to the formation for ciliated cysts [14].
It may be that these differing theories are substantial and that ciliated cysts of the skin and soft tissue form part of a heterogenous group of lesions developing from different histologic and embryonic structures. Hung et al. have proposed that the term cutaneous ciliated cyst be abandoned for "cutaneous Mullerian cysts" for those cysts which show features of Mullerian origin. They also propose the use of cutaneous ciliated eccrine cysts for the other group of cysts which occur in males and appear to be derived from ciliated metaplasia occurring in eccrine cells. Bivin Jr. et al. compared eccrine sweat glands with CCC histologically, immunohistochemically, and ultrastructurally and found them "completely unrelated" [15].

In this instance, the cyst was located in the upper thigh and showed strong staining not only for ER and PR but also for PAX-8 and WT1. These findings strongly support a Mullerian origin as mentioned by previous authors. Interestingly, unlike most cases of cutaneous ciliated cysts reported in the literature, our case showed no definitive evidence of cutaneous connection. A previously reported case with no attachment to skin was found in a postmenopausal woman on hormone replacement therapy with estrogen and gestagen [3]. We suggest the term ectopic Mullerian cyst be substituted for these rare lesions, eliminating the word cutaneous since a 
TABLE 1: List of previously reported cases of ciliated cutaneous cysts from 1890 to 2015. A total of 60 cases were reported, of which 50 were in female patients and 10 in males. Forty-eight (48) of these lesions were located in the lower extremity and its vicinity including the inguinal region, scrotum, perineum, buttock, gluteal cleft, and sacrococcygeal region. The other locations included the back, neck, scalp, cheek, abdominal wall, umbilicus, paravertebral region, and thumb. The reported ages ranged from 7 to 60 .

\begin{tabular}{|c|c|c|c|c|c|c|}
\hline Number & Year & Sex & Age & Location & Duration & Authors \\
\hline 1 & 1890 & Female & 15 & Back & Recent & Hess \\
\hline 2 & 1969 & Female & 39 & Left leg & $>10$ years & Clark \\
\hline \multirow[t]{3}{*}{$3-6$} & 1970 & Female & $15-27$ & Thigh $\times 2$ & 2 to several years & Butterworth et al. \\
\hline & & Female & & Right buttock & & \\
\hline & & Female & & Knee & & \\
\hline \multirow[t]{4}{*}{$7-17$} & 1978 & Female & $15-30$ & Buttock & Weeks to 5 years & Farmer, Helwig \\
\hline & & Female & & Thigh $\times 4$ & & \\
\hline & & Female & & Calf $\times 4$ & & \\
\hline & & Female & & Foot $\times 2$ & & \\
\hline 18 & 1980 & Female & 33 & Right sole & 2 months & True, Golitz \\
\hline 19 & 1982 & Female & 15 & Thigh & 7 months & Park et al. \\
\hline 20 & 1982 & Male & 42 & Heel & 5 years & Leonforte et al. \\
\hline 21 & 1983 & Female & 36 & Left foot & Early teens & Ross, Schwartz \\
\hline 22 & 1990 & Female & 42 & Right buttock & Long standing & Al-Nafussi, Carder \\
\hline 23 & 1990 & Female & 18 & Left buttock & 4 years & Varma et al. \\
\hline 24 & 1993 & Female & 22 & Scapula & Long standing & Sabourin et al. \\
\hline 25 & 1994 & Female & 20 & Scalp & 3 years & Sickel et al. \\
\hline 26 & 1994 & Male & 28 & Left foot & Not stated & Trotter et al. \\
\hline 27 & 1995 & Female & 16 & Left buttock & Recent & Biernat, Biernat \\
\hline 28 & 1995 & Female & 14 & Right thigh & 10 months & Cortes-Franco et al. \\
\hline 29 & 1995 & Female & 19 & Right buttock & 2 years & Tachibana et al. \\
\hline 30 & 1995 & Female & 17 & Right sole & 2 years & Osada et al. \\
\hline 31 & 1995 & Male & 27 & Right sole & 2 years & Ashton \\
\hline 32 & 1997 & Male & 60 & Perineal area & 2 years & Sidoni et al. \\
\hline 33 & 1997 & Female & 11 & Left foot & 1 year & Innocenzia et al. \\
\hline 34 & 1999 & Female & 23 & Right lower leg & 1 year & Yokozaki et al. \\
\hline 35 & 2000 & Female & 12 & Sacrococcygeal & Months & Dini et al. \\
\hline 36 & 2001 & Female & 13 & Sacrococcygeal & 1 year & Lee et al. \\
\hline 37 & 2002 & Female & 14 & Lower abdomen & 3 months & Fontaine et al. \\
\hline 38 & 2002 & Male & 53 & Right cheek & 2 years & Ohba et al. \\
\hline 39 & 2002 & Female & 18 & Abdomen & 6-7 months & Vadmal et al. \\
\hline 40 & 2004 & Male & 54 & Perineum & New discovery & Santos et al. \\
\hline 41 & 2006 & Male & 56 & Right inguinal area & 3 years & Lee et al. \\
\hline 42 & 2006 & Female & 41 & Umbilicus & 3 months & Kim et al. \\
\hline 43 & 2007 & Female & 16 & Left thigh & 1 year & Chong et al. \\
\hline 44 & 2008 & Female & 54 & Paravertebral & 8 years & Businger et al. \\
\hline 45 & 2008 & Male & 15 & Scrotal area & Recent & Pérez Valcárcel et al. \\
\hline 46 & 2009 & Female & 51 & Left leg & 2 years & Torisu-Itakura \\
\hline 47 & 2010 & Female & 13 & Right leg & 2 years & Bivin et al. \\
\hline 48 & 2011 & Female & 25 & Not stated & 2 years & Gelincik \\
\hline 49 & 2011 & Female & 48 & Right heel & Several years & Stevens, Sarma \\
\hline 50 & 2011 & Female & 14 & Right knee & 4 years & Ashturkar et al. \\
\hline 51 & 2012 & Female & 16 & Left thumb & Not stated & Hung et al. \\
\hline 52 & 2013 & Female & 15 & Right hip & 1 year & Rodrigo-Nicolás et al. \\
\hline 53 & 2014 & Female & 20 & Left knee & 10 years & Joehlin-Price et al. \\
\hline 54 & 2014 & Female & 22 & Pretibial & 2-3 years & Joehlin-Price et al. \\
\hline 55 & 2014 & Female & 13 & Gluteal cleft & 1 month & Oh et al. \\
\hline
\end{tabular}


TABLE 1: Continued.

\begin{tabular}{lcccccc}
\hline Number & Year & Sex & Age & Location & Duration & Authors \\
\hline 56 & 2014 & Female & 53 & Scalp & Lifelong & Reserva et al. \\
57 & 2014 & Female & 38 & Popliteal fossa & 1 year & Kavishwar et al. \\
58 & 2015 & Male & 14 & Scrotum & Not stated & Swarbrick et al. \\
59 & 2015 & Male & 7 & Left posterior neck & 3 years & Kim, Kim \\
60 & 2015 & Female & 14 & Right lower leg & 1 year & Keisling et al. \\
\hline
\end{tabular}

subset of these cysts is not related to the skin, as shown by the current case.

\section{Competing Interests}

The authors declare that there is no conflict of interests with respect to this paper.

\section{References}

[1] E. R. Farmer and E. B. Helwig, "Cutaneous ciliated cysts," Archives of Dermatology, vol. 114, no. 1, pp. 70-73, 1978.

[2] A. I. Al-Nafussi and P. Carder, "Cutaneous ciliated cyst: a case report and immunohistochemical comparison with fallopian tube," Histopathology, vol. 16, no. 6, pp. 595-598, 1990.

[3] A. P. Businger, H. Frick, M. Sailer, and M. Furrer, "A ciliated cyst in the posterior mediastinum compatible with a paravertebral Mullerian cyst," European Journal of Cardio-Thoracic Surgery, vol. 33, no. 1, pp. 133-136, 2008.

[4] A. S. Joehlin-Price, J.-H. Huang, J. S. Brooks, T. J. Scharschmidt, and O. H. Iwenofu, "PAX-8 expression in cutaneous ciliated cysts: evidence for Müllerian origin," American Journal of Dermatopathology, vol. 36, no. 2, pp. 167-170, 2014.

[5] D. G. Fontaine, H. Lau, S. K. Murray, R. B. Fraser, and J. R. Wright Jr., "Cutaneous ciliated cyst of the abdominal wall: a case report with a review of the literature and discussion of pathogenesis," American Journal of Dermatopathology, vol. 24, no. 1, pp. 63-66, 2002.

[6] Y. Kim and H. Kim, "The cutaneous ciliated cyst in young male: the possibility of ciliated cutaneous eccrine cyst," Case Reports in Medicine, vol. 2015, Article ID 589831, 5 pages, 2015.

[7] T. Hung, A. Yang, S. W. Binder, and R. L. Barnhill, "Cutaneous ciliated cyst on the finger: a cutaneous mullerian cyst," American Journal of Dermatopathology, vol. 34, no. 3, pp. 335-338, 2012.

[8] M. Dini, G. L. Russo, G. Baroni, and M. Colafranceschi, "Cutaneous ciliated cyst: a case report with immunohistochemical evidence for dynein in ciliated cells," American Journal of Dermatopathology, vol. 22, no. 6, pp. 519-523, 2000.

[9] N. Ohba, D. Tsuruta, M. Muraoka, T. Haba, and M. Ishii, "Cutaneous ciliated cyst on the cheek in a male," International Journal of Dermatology, vol. 41, no. 1, pp. 48-49, 2002.

[10] J. S. Lee, Y. C. Kim, and E. S. Lee, "Cutaneous ciliated cyst of the inguinal area in a man," Journal of Dermatology, vol. 33, no. 2, pp. 146-149, 2006.

[11] J. Pérez Valcárcel, G. Peón Currás, M. E. Sánchez Arca, I. Rodríguez Gómez, and A. Sousa Escandón, "Cutaneous ciliated cyst of the scrotal skin. A case report with discussion of pathogenesis," Actas Urologicas Espanolas, vol. 32, no. 8, pp. 843-846, 2008.

[12] N. Swarbrick, N. T. Harvey, and B. A. Wood, "Cutaneous ciliated cyst of the scrotum," Pathology, vol. 47, no. 6, pp. 593-595, 2015.

[13] J. F. Leonforte, "Cutaneous ciliated cystadenoma in a man," Archives of Dermatology, vol. 18, no. 12, pp. 1010-1012, 1982.

[14] A. Sidoni and E. Bucciarelli, "Ciliated cyst of the perineal skin," American Journal of Dermatopathology, vol. 19, no. 1, pp. 93-96, 1997.

[15] W. W. Bivin Jr., J. E. Heath, C. B. Drachenberg, E. D. Strauch, and J. C. Papadimitriou, "Cutaneous ciliated cyst: a case report with focus on mullerian heterotopia and comparison with eccrine sweat glands," American Journal of Dermatopathology, vol. 32, no. 7, pp. 731-734, 2010. 


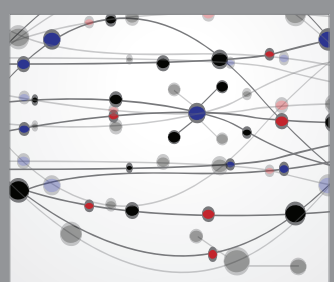

The Scientific World Journal
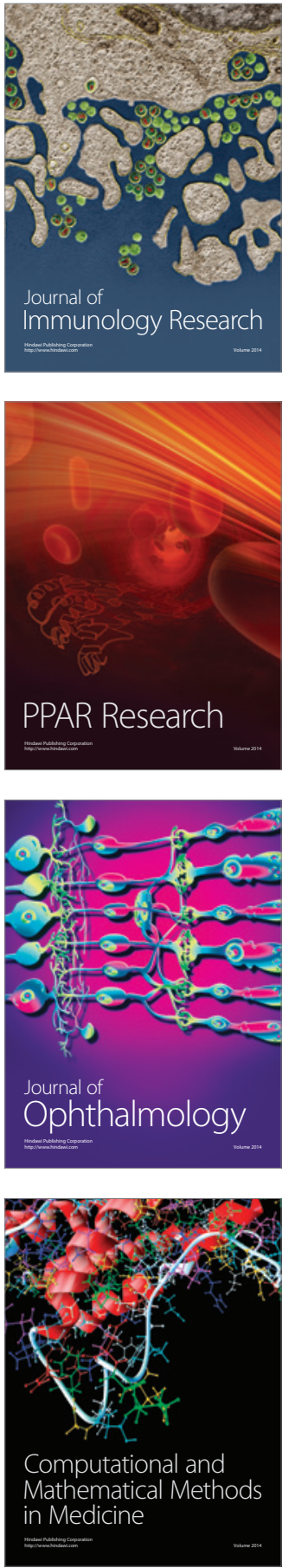

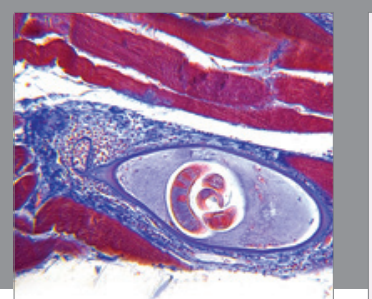

Gastroenterology Research and Practice

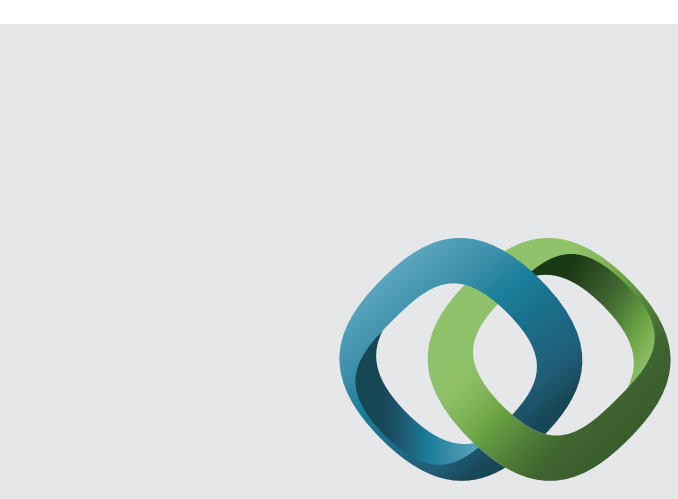

\section{Hindawi}

Submit your manuscripts at

http://www.hindawi.com
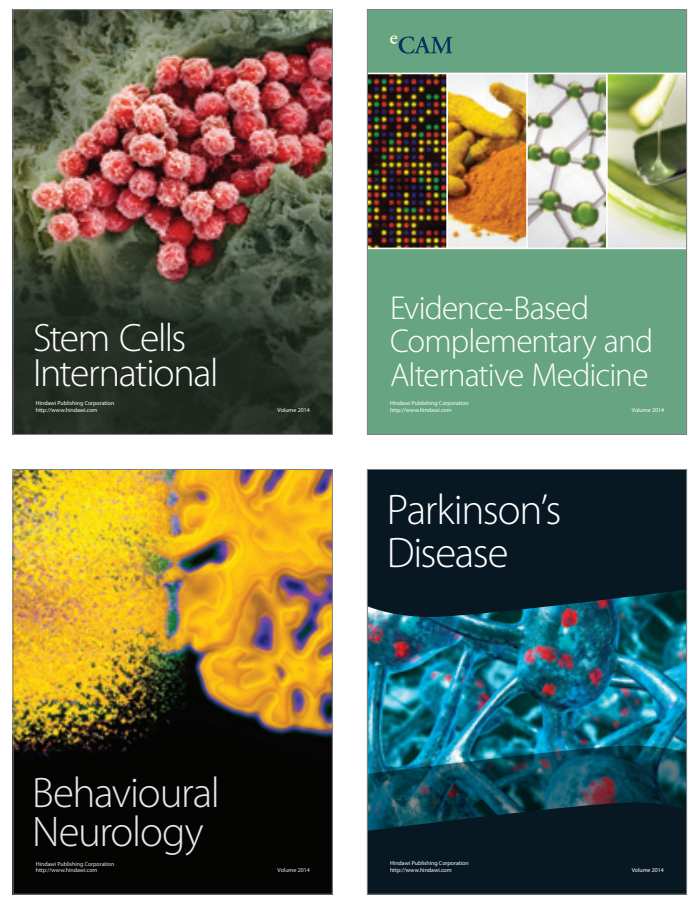
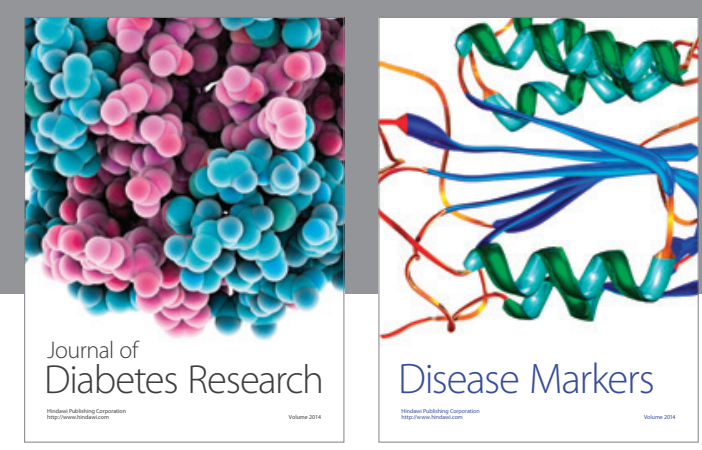

Disease Markers
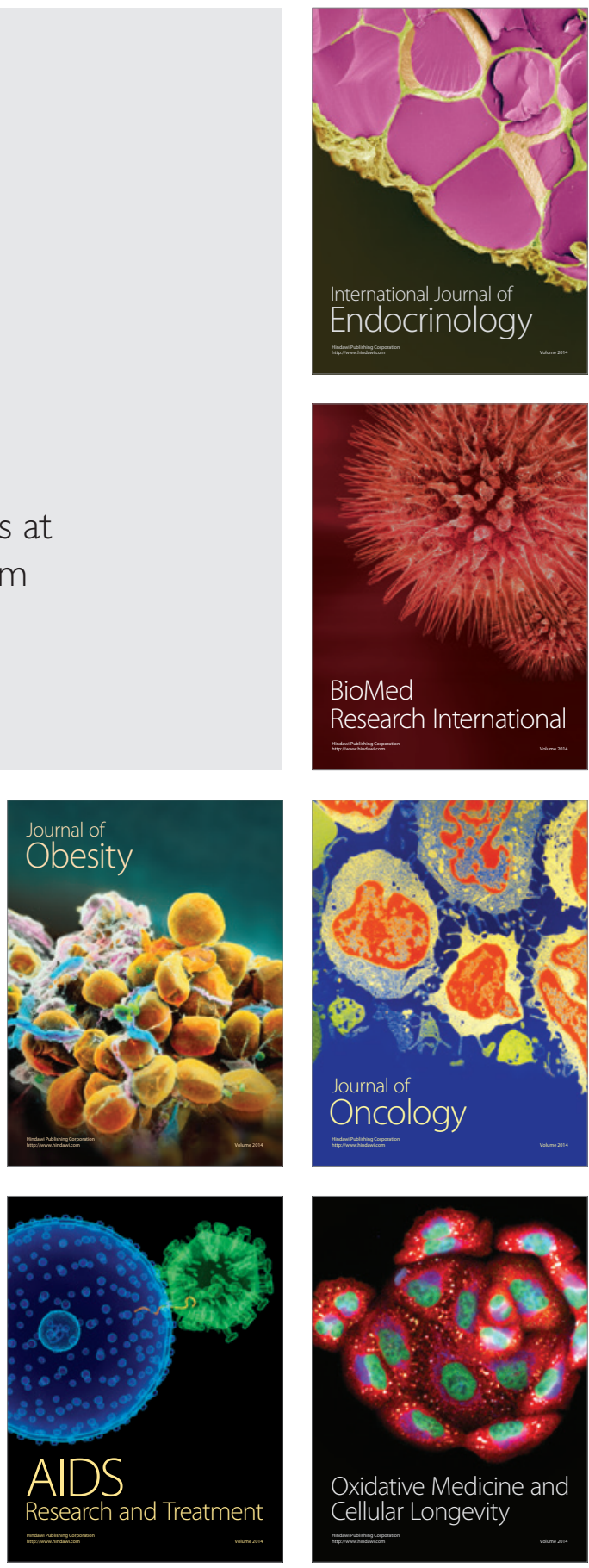